\title{
STABILISASI TANAH LEMPUNG DENGAN ARANG KAYU TERHADAP DAYA DUKUNG TANAH
}

\author{
Hamdan Solihin
}

Program Studi Teknik Sipil Universitas Muhammadiyah Sorong Jalan Pendidikan No 27 Kota Sorong, Propinsi Papua Barat

Email : hamdansolihin736@gmail.com

\begin{abstract}
ABSTRAK
Kabupaten sorong sebagaian besar salah satu kabupaten yang cukup maju dengan perkembangan di Provinsi Papua barat. Yang dapat bisa dilihat dari banyaknya pembangunan infraktruktur seperti perumahan, pusat pertokohan, jalan, dan kawasan komersial lainnya.Pada penelitian kali ini kondisi jalan yang bergelombang, retak - retak dan berlubang yang sering di jumpai oleh pengguna jalan di Kabupaten Sorong khususnya pada ruas jalan SP 4 kelurahan Makbalim Distrik Mayamuk Kabupaten Sorong, akibat dari jalan yang kurang baik menyebabkan terganggunya pengendara yang melintasi ruas jalan tersebut dan sering terjadi kecelakaan bagi pengguna motor maupun mobil. Sehingga tanah di wilayah tersebut perlu di stabilisasi. Tujuan penelitian ini adalah sUntuk menganalisa sifat-sifat fisis tanah asli dari ruas jalan SP 4 kelurahan Makbalim Distrik Mayamuk Kabupaten Sorong dan menganalisa pengaruh pencampuran bubuk arang kayu pada tanah lempung terhadap daya dukung tanah. Tahapan penelitian sebagai berikut Persiapan, Penyedian Benda UJi, Pemeriksaan Tanah Lempung, Kadar pencampuran tanah dengan bubuk arang kayu sebesar 5\%, 15\%, 25\%, dan 35\%. Pemeriksaan Sifat Fisis Tanah meliputi (Batas Atteberg,Berat Jenis,Kadar Air dan Analisa Saringan dan Hydrometer), Pemeriksaan Sifat Mekanis Tanah meliputi (Pemadatan dan CBR)
\end{abstract}

Kata Kunci : Stabilisasi; Tanah Lempung; Arang Kayu; CBR 


\section{PENDAHULUAN}

\section{Latar Belakang}

Kabupaten sorong sebagaian besar salah satu kabupaten yang cukup maju dengan perkembangan di Provinsi Papua barat. Yang dapat bisa dilihat dari banyaknya pembangunan infraktruktur seperti perumahan, pusat pertokohan, jalan, dan kawasan komersial lainnya. Kondisi umum jaringan jalan di kabupaten sorong beberapa tahun belakangan ini terus mengalami penurunan. Beberapa masalah utama adalah kualitas kontruksi jalan yang belum optimal, daya dukung tanah yang rendah, pembebanan dari muatan kendaraan, bencana alam seperti banjir, longsor dan gempa bumi. Maka Pemerintah daerah setempat saat ini terus menerus melakukan pembangunan jalan - jalan di Kabupaten sorong untuk meningkatkan sarana lalu lintas dalam mendukung perekonomian masyarakat kabupaten sorong. Pada penelitian kali ini kondisi jalan yang bergelombang, retak - retak dan berlubang yang sering di jumpai oleh pengguna jalan di Kabupaten Sorong khususnya pada ruas jalan SP 4 kelurahan Makbalim Distrik Mayamuk Kabupaten Sorong, akibat dari jalan yang kurang baik menyebabkan terganggunya pengendara yang melintasi ruas jalan tersebut dan sering terjadi kecelakaan bagi pengguna motor maupun mobil. Sehingga tanah di wilayah tersebut perlu di stabilisasi dengan menggunakan metode stabilisasi tanah. Stabilasasi adalah proses untuk memperbaiki sifat - sifat tanah dengan cara menambahkan sesuatu pada tanah tersebut agar daya dukung tanah meningkat. Metode yang digunakan adalah metode stabilisasi kimiawi, stabilisasi kimiawi yaitu menambah kekuatan dan kuat dukung tanah dengan cara mengurangi atau menghilangkan sifat - sifat teknis tanah yang 
kurang menguntungkan dengan mencampurkan tanah dengan bahan campuran bubuk arang kayu. Hal ini dibuktikan dengan hasil uji kandungan unsur kimia bubuk arang kayu yang dilakukan di Laboratorium Kimia Analitik Jurusan Kimia Fakulitas Mipa Universitas Gadjah Mada Yogyakarta, bubuk arang kayu mengandung unsur kimia antara lain karbon (C), aluminium (Al), Silika (Si), Kalsium (Ca), Magnesium (Mg), dan Fosfor (P), Untuk itu diperlukan upaya stabilisasi tanah lempung sebelum membangun konstruksi di atas tanah dasar yang memiliki daya dukung rendah. Penelitian ini menggunakan bahan bubuk arang kayu sebagai bahan campuran dalam menstabilisasi tanah diharapkan akan diperoleh campuran dengan mutu baik dan meningkatkan daya dukung tanah yang baik.

\section{Tujuan Penelitian}

Adapun dari tujuan penelitian ini adalah sebagai berikut :

1. Untuk menganalisa sifat-sifat fisis tanah asli dari ruas jalan SP 4 kelurahan Makbalim Distrik Mayamuk Kabupaten Sorong.

2. Untuk menganalisa pengaruh pencampuran bubuk arang kayu pada tanah lempung terhadap daya dukung tanah.

\section{STATE OF THE ART}

Adapun penelitian terdahulu yang terkait dengan penelitian ini adalah sebagai berikut :

1. Menurut Sengeoris (2011) menyebutkan bahwa :

a) Tanah asli diidentifikasi sebagai tanah A-7-6 pada sistem klasifikasi AASHTO (1986). Ini juga tanah liat plastisitas tinggi $(\mathrm{CH})$ menurut sistem klasifikasi terpadu (USC). 
b) Pengaruh dengan pencampuran bubuk arang kayu menunjukkan penurunan umum pada Berat volume kering (OMC) dan Kadar air (MDD) mengalami kenaikan.

c) Variasi CBR dengan peningkatan bubuk arang kayu dari 5 sampai $7,5 \%$ serta perawatan 0,3 , dan 7 hari untuk mengetahui besarnya pengaruh yang terjadi pada tanah terhadap nilai sifat fisis dan mekanis tanah.

d) Nilai berat volume kering maksimum terkecil dan kadar air optimum terbesar terdapat pada tanah persentase campuran 7,5\% dengan lama perawatan 7 hari sebesar 1,213 gr/cm3 dan 33,10\%.Sedangkan nilai berat volume kering maksimum terbesar terdapat pada tanah asli sebesar $1,265 \mathrm{gr} / \mathrm{cm} 3$.

e) Hasil uji CBR menunjukkan kenaikan seiring bertambahnya persentase campuran dan lama perawatan. Nilai CBR terbesar terdapat pada tanah campuran $7,5 \%$ dengan lama perawatan 7 hari sebesar $27 \%$ sedangkan nilai CBR terkecil sebesar $12 \%$ pada tanah campuran 5\% dengan lama perawatan 0 hari.

\section{METODE}

\section{Tahapan Penelitian}




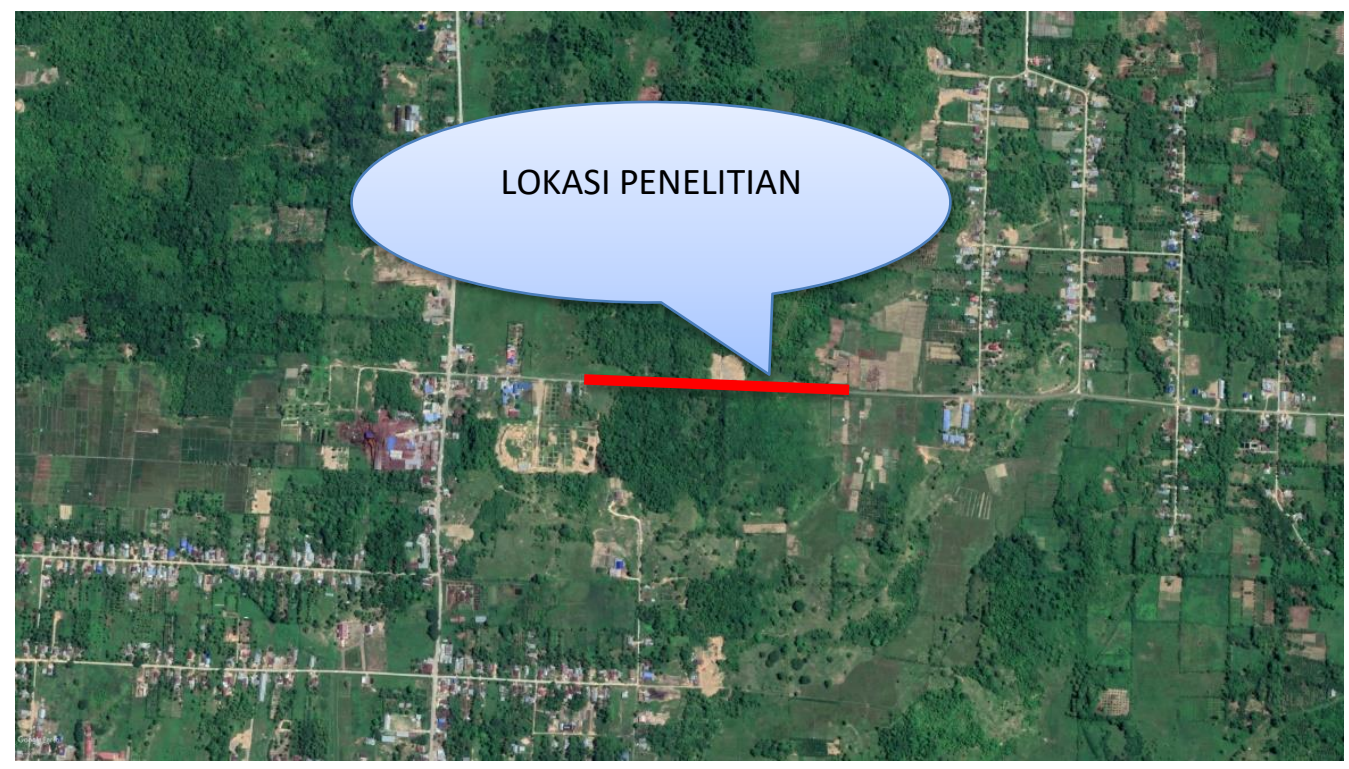

Gambar. Pada pada ruas jalan SP 4 kelurahan Makbalim Distrik Mayamuk

Tahapan penelitian yang digunakan adalah sebagai berikut :

1. Persiapan \& Penyedian Benda UJi

2. Pemeriksaan Tanah Lempung

3. Pemeriksaan Sifat Fisis Tanah
a. Batas Atteberg
b. Berat Jenis
c. Kadar Air
d. Analisa Saringan dan Hydrometer

4. Pemeriksaan Sifat Mekanis Tanah
a. Pemadatan (Compaction)
b. CBR

5. Pengujian Tanah Lempung + bubuk arang kayu 2\%,4\%, $8 \%, 12 \%$
a. Berat Jenis
b. Batas Atteberg 


\section{c. Pemadatan (Compaction)}

d. CBR

Semua metode penulisan dan analisa dalam artikel ilmiah ini merujuk pada panduan penulisan tugas akhir Fakultas Teknik Universitas Muhammadiyah Sorong tahun 2014 (Pristianto, Amri, \& Rusdi, 2014).

\section{REFERENSI}

Ilham, A. (2017) Perubahan Nilai Cbr Lempung Ekspansif Dengan Penambahan Arang Kayu Sebagai Stabilitator Kimia.

Hardiyatmo, H. C. (2010). Stabilisasi Tanah Untuk Perkerasan Jalan, Universitas Gadjah Mada, Yogyajakarta

Katarina Martina Nelda, A. (2006). Penelitian Kapasitas Adsorpsi Zat Warna Ci Reactive Orange 16 Oleh Arang Kayu, Arang Tempurung Kelapa Dan Karbon Aktif Dengan Menggunakan Persamaan Isoterm Model Freundlich Dan Langmuir (Doctoral Dissertation, Fakultas Teknik Unpas).

Pandiangan, B., Iswan, I., \& Jafri, M. (2016). Pengaruh variasi waktu pemeraman terhadap daya dukung tanah lempung dan lanau yang distabilisasi menggunakan semen pada kondisi tanpa rendaman (Unsoaked). Jurnal Rekayasa Sipil dan Desain, 4(2), 256-275.

Pristianto, H., Amri, I., \& Rusdi, A. (2014). Pedoman Penulisan Tugas Akhir Fakultas Teknik Universitas Muhammadiyah Sorong 2014. 
Sengeoris, M., \& Qunik Wiqoyah, S. T. (2016). Pemanfaatan Bubuk Arang Kayu Sebagai Bahan Stabilisasi Terhadap Kuat Dukung Tanah Lempung Sukodono Dengan Variasi Perawatan (Doctoral dissertation, Universitas Muhammadiyah Surakarta).

Soedarmo, G. D., \& Purnomo, E. (1997). Mekanika Tanah 1, Yogyakarta

Sutarman, E. (2013). Konsep \& Aplikasi Mekanika Tanah 1, Yogyakarta 